\title{
The safety of early administration of oral fluid following general anesthesia in children undergoing tonsillectomy: a prospective randomized controlled trial
}

\author{
Meng-Hang $\mathrm{Wu}^{1+}$, Chang-qing Liư ${ }^{2+}$, Xiao-qi Zeng ${ }^{3}$, An-na $\mathrm{Jia}^{3}$ and Xiao-rong Yin ${ }^{3 *}$
}

\begin{abstract}
Background: The feasibility and safety of administrating a small amount of oral fluid to children in the early recovery period following tonsillectomy under general anesthesia to reduce the thirst and its associated restlessness remain unknown.

Methods: This study was approved by the institutional ethics committee and adhered to the CONSORT guidelines. Pediatric patients undergoing tonsillectomy who met the inclusion and exclusion criteria of our study were randomized into the study and control groups. In the study group, patients were given a small amount of water instantly after recovering from general anesthesia, which included the recovery of the cough and deglutition reflex, and attaining grade $V$ of muscle strength. The control group was given a small amount of water at 4 to $6 \mathrm{~h}$ after the operation. The incidence of nausea and vomiting and the degree of thirst relief were measured and compared between the two groups.
\end{abstract}

Results: Three hundred patients were randomized into each group. There was no significant difference in the incidence of nausea and vomiting at 20 min after drinking water between the two groups $(P>0.05)$. The thirst score of children over 5 years old in the study group was significantly lower than that of the control group $(P<0.05)$.

Conclusion: Early administration of a small amount of oral fluid to children following tonsillectomy and recovering from general anesthesia is not only safe but also effective in reducing postoperative thirst.

Trial registration: Current Controlled Trials ChiCTR1800020058, 12-12-2018.

Keywords: Tonsillectomy, Recovery from general anesthesia, Oral fluid, Safety, Feasibility

\section{Background}

Surgery is currently the main method to treat various diseases, but it is also a stress response for patients, such as preoperative fasting and deprived of drinking, surgical trauma, postoperative anesthesia recovery, etc. Therefore,

\footnotetext{
* Correspondence: Icqing915@126.com

${ }^{+}$Meng-Hang Wu and Chang-qing Liu contributed equally as the first author. ${ }^{3}$ Department of Anesthesiology, Anesthesia Surgery Center of West China Hospital / West China School of Nursing, Sichuan University, No. 37, Guoxue Alley, Wuhou District, Chengdu, Sichuan 610041, China

Full list of author information is available at the end of the article
}

perioperative nursing is of vital importance for postoperative rehabilitation of patients [1]. Traditionally, in order to avoid adverse events such as nausea, vomiting and coughing caused by the residual effects of anesthetics after general anesthesia, postoperative patients are routinely prohibited from drinking for 4-6 h [2]. Study [3] showed intraoperative anesthetic such as fentanyl and remifentanil would delay the time of oral intake. Some studies [47] have shown that oral fluid in the early postoperative period has great benefit to patients undergoing general anesthesia, which include rapid return to normal diet,

(c) The Author(s). 2021 Open Access This article is licensed under a Creative Commons Attribution 4.0 International License, which permits use, sharing, adaptation, distribution and reproduction in any medium or format, as long as you give appropriate credit to the original author(s) and the source, provide a link to the Creative Commons licence, and indicate if changes were made. The images or other third party material in this article are included in the article's Creative Commons licence, unless indicated otherwise in a credit line to the material. If material is not included in the article's Creative Commons licence and your intended use is not permitted by statutory regulation or exceeds the permitted use, you will need to obtain permission directly from the copyright holder. To view a copy of this licence, visit http://creativecommons.org/licenses/by/4.0/. The Creative Commons Public Domain Dedication waiver (http://creativecommons.org/publicdomain/zero/1.0/) applies to the data made available in this article, unless otherwise stated in a credit line to the data. 
reduced thirsty, early bowl movement, early ambulation and increased satisfaction. As the enhanced recovery after surgery model has been popularized in recent years, oral intake could be administrated $1-2 \mathrm{~h}$ after awake from anesthesia for children undergoing minor surgery [4] and minimizing discontinuation of oral hydration for all patients has been encouraged [8]. Our previous studies [57] reported that earlier than $2 \mathrm{~h}$ in the postoperative period, even within 20 min of waking from anesthesia, oral hydration did not increase the occurrence of postoperative nausea and vomiting or inhibit gastric peristalsis in the children and adult patients undergoing non-gastrointestinal surgery except tonsillectomy under general anesthesia, which is safe and well tolerated. Not only that, it has become accepted that early oral hydration in the postoperative period could promote early recovery and prevent postoperative ileus [9].

In our setting, tonsillectomy is a solution to a series of symptoms in pediatric patients, such as sleep-disordered breathing caused by tonsillar hypertrophy, obstruction of normal breathing, and influence on the development of children. Therefore, tonsillectomy is a relatively common procedure in pediatric patients $[10,11]$. Since tonsillectomy involves the oropharynx of pediatric patients, postoperative oral hydration may be affected. In addition, our previous studies [6,7] also showed that patients routinely fasted for more than $15 \mathrm{~h}$ before surgery, and more than $81 \%$ of the children returned to the PostAnesthesia Care Unit (PACU) after surgery were thirsty and wanted to have oral fluid. The recovery period following general anesthesia is a period for children to fully regain their important physiological functions but is also a period associated with a high risk of adverse events as a result of restlessness $[12,13]$, which is not uncommon in children and adolescents during the recovery period following general anesthesia, especially among male children [14]. Thirst is common in children undergoing tonsillectomy and often causes severe agitation in the recovery period following anesthesia, leading to increased oxygen consumption, arrhythmia, wound bleeding, etc. In severe cases, patients may inadvertently pull out the infusion tube, urinary catheter, and other medical equipment, which will adversely affect the postoperative recovery [15].

It is well known that children have a higher proportion of water in their bodies than adults, so postoperative fluid management is more important for the pediatrics' patients. Relevant clinically research is necessary, which should be carried out to explore and consider giving a small amount of oral fluid to children in the recovery period following tonsillectomy under general anesthesia to reduce thirst and its associated restlessness. However, there is little known about the benefit and timing of oral intake for the pediatric patients undergoing tonsillectomy in PACU, and it remains uncertain whether early oral hydration in the PACU is possible after tonsillectomy. Hence, our study aimed to examine the feasibility and safety of early administration of oral fluid and to determine if such intervention would provide thirst relief in this group of patients. The impact of this policy on the primary outcome (thirst scale score) and secondary outcomes (complications including cough, aspiration, nausea, and vomiting) have been observed.

\section{Methods \\ Design}

We conducted a prospective, randomized, controlled trial to examine the feasibility and safety of early administration of oral fluid and to determine if such intervention would provide thirst relief in the pediatric patients undergoing tonsillectomy.

This study was approved by the ethics committee of our institution (2017 Review No. 231) with the registration number ChiCTR1800020058 (http://www.chictr.org. cn/showproj.aspx?proj=33847, registered on the 12th December 2018) and adhered to the CONSORT guidelines. We interviewed patients and their parents and then explained the study protocols on the day before surgery. Written informed consent obtained from the parents of all participating children in the surgery day.

\section{Study population and setting}

In this study, the relief rate of thirst administrated oral fluid in PACU after surgery was selected as an important indicator for the calculation of the sample size. Our previous studies [5-7] showed that the thirsty proportion about $81 \%$ of children without drinking water after recovering from anesthesia in PACU. The preset thirst relief rate was $64 \%$, which was less than $71 \%$ of the previous studies (after $20 \mathrm{~min}$ a small amount of water has been administrated immediately to the patients when postoperative recovering from anesthesia). Considering that the rate of loss of follow-up was about $20 \%$, the sample size was calculated by comparing rates of independent two groups sample. The calculated sample size was 126 cases, that was, at least 126 children were included in each of the study group and control group as the research objects. A total of 300 children undergoing tonsillectomy in the West China Hospital of Sichuan University were recruited and randomized into 2 groups by using the computer-generated random number list: the study group $(n=150)$ and the control group $(n=$ $150)$. In the study group, patients were given a small amount of water instantly after recovering from general anesthesia whereas in the control group, patients were given a small amount of water at 4 to $6 \mathrm{~h}$ after recovering from general anesthesia. The number of patients 
express Fig. 1. Randomization, treatment, and inclusion in analysis.

\section{Study protocol}

When all patients were sent to PACU after their surgery, standard monitoring including electrocardiograph, noninvasive blood pressure monitoring, pulse oximeter, capnograph were applied by trained PACU anesthesiologists and nurses. The administration of oral fluid was introduced in stages. In the study group, when children regained full consciousness following general anesthesia, they were assessed instantly on several criteria: the recovery of coughing and swallowing reflex, no nausea and vomiting, muscle strength returned to level $\mathrm{V}$, stable vital signs, and had a desire for water consumption. Once these criteria were fulfilled, the procedures for oral fluid (water) administration would then be carried out.
First, the child's lips and mouth would be wet with 1-5 $\mathrm{ml}$ water. Then, the head of the child would be turned to one side and the child would be given water to drink by a fixed systemically trained anaesthesia monitoring nurse. Depending on the condition of the child, drinking through a straw or with a syringe containing a small amount of water to be injected into the mouth several times. The child would be observed closely for any discomfort such as choking or coughing. If there was no discomfort, the remaining water would then be injected slowly into the mouth, or the child would be encouraged to drink him/herself. Total water volume was restricted to $1.5 \mathrm{~mL} / \mathrm{kg}$. After this single fluid intake patients in the study group received no additional fluid until 4-6 h after recovering from general anesthesia, by which time patients had been transferred from the PACU to the ward (to allow ward nurses to be blinded to patient group). In

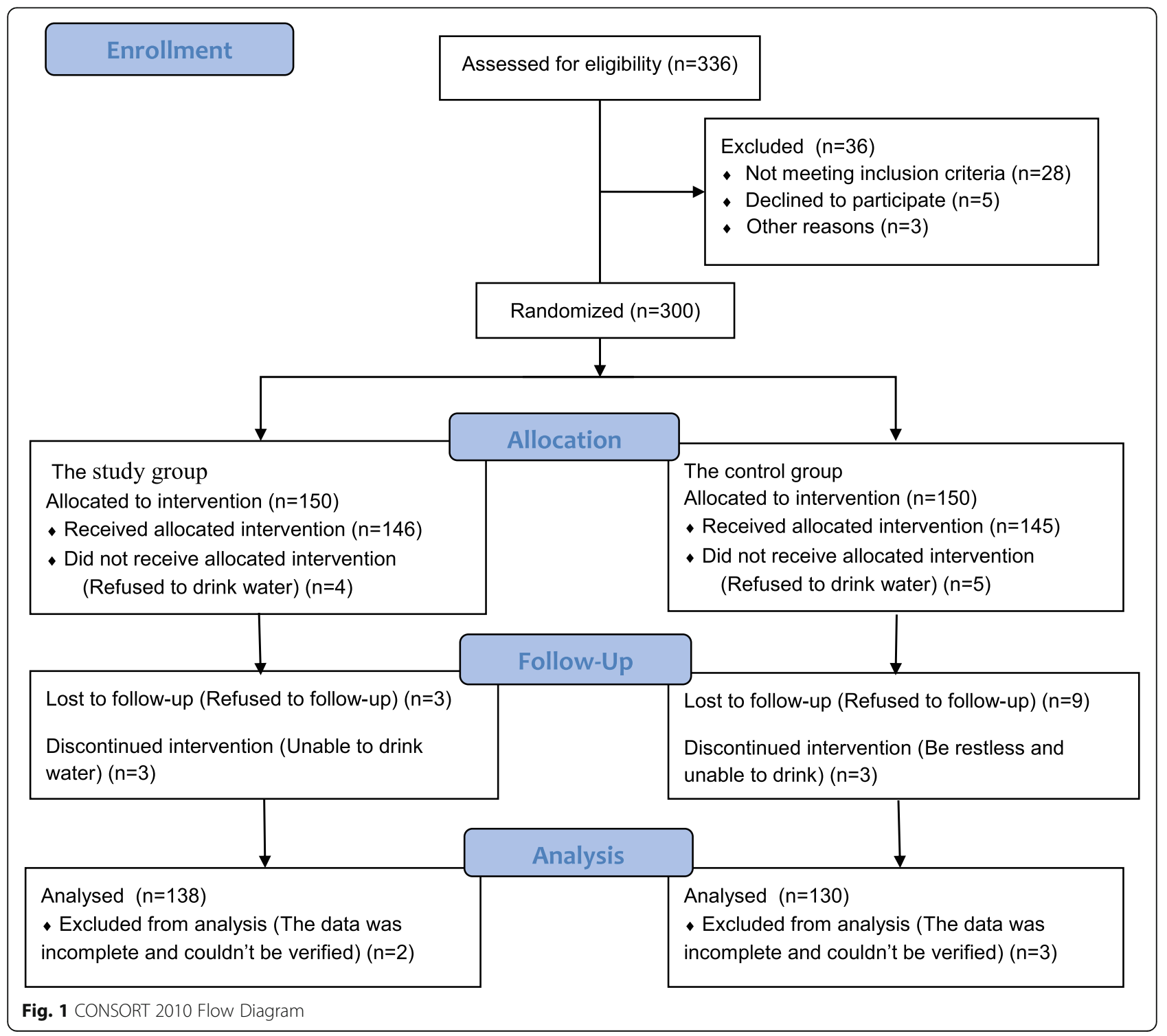


the control group, similar criteria were assessed before children were allowed to drink a small amount of water at 4 to $6 \mathrm{~h}$ after recovering from general anesthesia, as usual. All patients received intravenous fluids.

The inclusion criteria were: Children aged 3-12 years old undergoing elective tonsillectomy; American Society of Anesthesiologists (ASA) class I-III; Fulfilled the criteria for oral fluid administration as outlined above; Analgesics were administered over $20 \mathrm{~min}$.

The exclusion criteria were: Sick children with bleeding, dysphagia, nausea, and vomiting, or needing active resuscitation in PACU.

\section{Measurements}

Primary outcomes was thirst relief, which assessed by thirst scale score using the self-rating thirst scale, consisted of the $0-100 \mathrm{~mm}$ verbal numeric scale $(0=$ not thirsty to $100=$ very thirsty) according to patients' thirst level [5-7]. Secondary outcomes were the complications including cough, aspiration, nausea and vomiting. After drinking water, patients were observed closely for at least 20 min for complications including cough, aspiration, nausea, and vomiting, then thirst relief was assessed and recorded. The number of patients expressing a desire to drink water was also obtained immediately after recovery from general anesthesia and $20 \mathrm{~min}$ later. These patients were observed in the PACU for $2 \mathrm{~h}$ and then sent to the ward. On admission to the ward, the ward surgeons and nurses were blinded to the policy. When the patients return to the ward, drinking water is done as usual.

\section{Statistical analysis}

SPSS 23.0 was used for statistical analysis. The chisquare test and Fisher's test were performed to analyze categorical data, whereas the Student's t-Test was used for continuous data. A $P$-value of $<0.05$ was considered statistically significant.

\section{Results}

\section{Patient characteristics between the two groups}

A total of 300 patients were recruited into our study for randomization. However, 15 of these refused to drink water, 12 were lost to follow-up, and 5 had incomplete data collection which could not be verified. Therefore, 268 cases were included in the analyses. Of these, 138 patients were in the study group and 130 were in the control group (Fig. 1), with the age ranging from 3 to 12 years old. The amount of water consumed was less than $1 \mathrm{ml} / \mathrm{kg}$ body weight, approximately $13.56 \pm 19.82 \mathrm{ml}$ in the study group. Patients characteristics were compared (Table 1), which showed no statistical difference $(P>0.05)$ between the study and the control groups.

\section{Comparison of perioperative anesthetic drugs usage between the two groups}

The use of atracurium was significantly higher in the control group compared with the study group $(P=0.02)$. There was no other statistically significant difference between the two groups in the use of perioperative anesthetic drugs (Table 2).

\section{Comparison of the thirst relief rate and thirst scores between the two groups}

In the study, we found that children under 5 years old were not very good at thirst score, so children aged 3-5 years old were not included in the thirst score analysis. The thirst relief rate was analyzed statistically in all the children. Before oral fluid was administered, the thirst rate of patients in the study group was $91.3 \%(126 / 138)$ and that of patients in the control group was $93.1 \%(121 /$ $130)$, with no statistically significant difference $\left(x^{2}=\right.$ $0.291, P=0.589$ ). However, after $20 \mathrm{~min}$ of oral fluid was administered, the thirst rate of patients in the study group was $41.3 \%(57 / 138)$ and that of patients in the control group was $87.7 \%(114 / 130)$, the difference was statistically significant $\left(x^{2}=62.37, P<0.001\right)$. There were 189 children over 5 years old in our study, and there was no significant difference $(P>0.05)$ in the thirst score before oral fluid was given in the PACU. However, the thirst score in the study group after 20 min of oral fluid consumption in the PACU was significantly lower compared with the control group $(P=0.001)$, (Showed in Table 3).

\section{Comparison of the incidence of nausea and vomiting between the two groups}

There was no incidence of aspiration in this study. There was no significant difference in the incidence of nausea and vomiting between the two groups before and after oral fluid consumption at the PACU, or in the ward $(P>0.05)$. However, we observed incidences of nausea and vomiting occurred in the control group in the ward, although this difference was not statistically significant $(P=0.054)$ (Table 4).

\section{Discussion}

The finding of this prospective randomized controlled study showed that early oral fluid for pediatric patients immediately after undergoing tonsillectomy under general anesthesia, was not only safe and well tolerated, but also significantly relieved patients' thirst than delayed oral hydration. 
Table 1 Comparison of patients characteristics between the study and control groups

\begin{tabular}{|c|c|c|c|}
\hline Items & $\begin{array}{l}\text { Study group } \\
n=138\end{array}$ & $\begin{array}{l}\text { Control group } \\
n=130\end{array}$ & $\begin{array}{l}P \text { - } \\
\text { value }\end{array}$ \\
\hline Age (year), mean $\pm S D$ & $5.76 \pm 2.09$ & $5.87 \pm 1.96$ & 0.663 \\
\hline Gender $(n, \%)$ & & & 0.807 \\
\hline Male & $73(52.9)$ & $71(54.6)$ & \\
\hline Female & $65(47.1)$ & $59(45.4)$ & \\
\hline Weight $(\mathrm{Kg})$, mean $\pm \mathrm{SD}$ & $22.11 \pm 8.92$ & $22.44 \pm 7.74$ & 0.751 \\
\hline Preoperative fasting time $(h)$, mean $\pm S D$ & $10.34 \pm 2.57$ & $10.43 \pm 2.56$ & 0.765 \\
\hline Anesthesia time $(\mathrm{min})$, mean $\pm \mathrm{SD}$ & $68.33 \pm 22.80$ & $66.73 \pm 21.83$ & 0.558 \\
\hline Time of operation (min), mean \pm SD & $34.79 \pm 14.22$ & $34.97 \pm 17.42$ & 0.926 \\
\hline Intraoperative infusion volume $(\mathrm{ml})$, mean \pm SD & $190.25 \pm 120.79$ & $188.58 \pm 134.53$ & 0.914 \\
\hline ASA classification $(n, \%)$ & & & 0.966 \\
\hline । & $7(5.1)$ & $5(3.8)$ & \\
\hline$\|$ & $127(92.0)$ & $123(94.6)$ & \\
\hline III & $4(2.9)$ & $2(1.5)$ & \\
\hline
\end{tabular}

Pediatric patients undergoing tonsillectomy are usually allowed to start oral intake gradually at $6 \mathrm{~h}$ after recovering from general anesthesia. The types of oral intake include ice drinks, such as ice milk and pure ice cream without impurities which help to relieve pain and reduce the risk of bleeding. Fruit and juice are advised to avoid because these contain fruit acids, which may cause pain and affect wound healing by stimulating the wound [16]. After tonsillectomy, children are usually advised to stay quietly in bed, speak little, and avoid coughing forcefully to prevent bleeding. Study advocate that children should drink cold fluid on the day after surgery [17]. In our study, mineral water at normal room temperature was given to the children in the early phase of recovery from general anesthesia in the study group following tonsillectomy. We did not observe any adverse events such as bleeding and there was no increase in the incidence of nausea or vomiting. Our data suggested that early administration of oral fluid after general anesthesia for tonsillectomy is safe.

The most common symptoms after tonsillectomy are wound pain and pain upon swallowing. Some children

Table 2 Comparison of the anesthetic drugs usage between two groups

\begin{tabular}{|c|c|c|c|}
\hline Items & Study group $(N=138)$ & Control group $(N=130)$ & $P$-value \\
\hline Fentanyl $(n, \%)$ & $122(88.4)$ & $113(86.9)$ & 0.715 \\
\hline Sufentanil $(n, \%)$ & $13(9.4)$ & $20(15.4)$ & 0.192 \\
\hline Remifentanil $(n, \%)$ & $24(17.4)$ & $30(23.1)$ & 0.287 \\
\hline Sevoflurane $(n, \%)$ & $137(99.3)$ & $126(96.9)$ & 0.202 \\
\hline Atracurium $(n, \%)$ & $111(80.4)$ & $118(90.8)$ & 0.023 \\
\hline Propofol $(n, \%)$ & $127(92)$ & $115(88.5)$ & 0.410 \\
\hline Dexmedetomidine $(n, \%)$ & $80(58.0)$ & $67(51.5)$ & 0.326 \\
\hline Atropine $(n, \%)$ & $80(58.0)$ & $66(50.8)$ & 0.270 \\
\hline Tramadol (n,\%) & $56(40.6)$ & $59(45.4)$ & 0.460 \\
\hline Lidocaine $(n, \%)$ & $9(6.5)$ & $15(11.5)$ & 0.199 \\
\hline Ondansetron hydrochloride tablets $(n, \%)$ & $120(87.0)$ & $122(93.8)$ & 0.065 \\
\hline Midazolam (n,\%) & $120(87.0)$ & $106(81.5)$ & 0.243 \\
\hline Granisetron $(n, \%)$ & $5(3.6)$ & $5(3.8)$ & 1.000 \\
\hline Dexamethasone $(n, \%)$ & $102(73.9)$ & $96(73.8)$ & 1.000 \\
\hline Neostigmine $(n, \%)$ & $6(4.3)$ & $3(2.3)$ & 0.502 \\
\hline Hemocoagulase Bothrops Atrox for Injection $(n, \%)$ & $46(33.3)$ & $43(33.1)$ & 1.000 \\
\hline Penehyclidine $(n, \%)$ & $2(1.4)$ & $2(1.5)$ & 1.000 \\
\hline
\end{tabular}


Table 3 Comparison of the thirst relief rate and thirst scores between the two groups

\begin{tabular}{|c|c|c|c|}
\hline Items & Study group $(N=138)$ & Control group $(N=130)$ & $P$-value \\
\hline Thirst relief rate before oral fluid was administered $(n, \%)$ & $126(91.3 \%)$ & $121(93.1 \%)$ & 0.589 \\
\hline Thirst relief rate of 20 min after oral fluid was administered $(n, \%)$ & $57(41.3 \%)$ & $114(87.7 \%)$ & $<0.001$ \\
\hline Thirst scales just after recovery from anesthesia $(n=92)$, mean \pm SD & $46.85 \pm 40.43$ & $43.20 \pm 35.72$ & 0.660 \\
\hline Thirst scales 20 min after oral fluid was administered at PACU $(n=97)$, mean \pm SD & $36.52 \pm 36.30$ & $54.64 \pm 34.79$ & 0.001 \\
\hline
\end{tabular}

also experience nausea and vomiting. The routine use of intravenous dexamethasone in this setting has been reported to reduce the incidence of vomiting from $27-11 \%$ [18]. In our study, $73.8 \%$ of the children received dexamethasone intraoperatively, and the incidence of nausea and vomiting after the administration of oral fluid following general anesthesia was only $0.7 \%$. Such a low incidence of nausea and vomiting in our study may be related to the intraoperative use of dexamethasone and antiemetic drugs.

The study by Chen et al. [19] reported that the time of eating after general anesthesia for non-abdominal surgery should be determined by the extend of the operation, the method of anesthesia, and the children's reaction. For the body surface or limb surgery, the body reaction is relatively mild. Patients may not eat if they are still under the influence of anesthesia with nausea and vomiting. Hence, patients usually eat when they have fully recovered from anesthesia that their nausea and vomiting have subsided. In the ambulatory surgical setting, a study [20] has demonstrated no statistically significant difference in the incidence of nausea and vomiting within $24 \mathrm{~h}$ after minor surgery between the drinking and the non-drinking group. Another study [21] has shown that among pediatric patients undergoing adenotonsillectomy, there was a significantly higher incidence of emesis when patients were encouraged to drink compared to patients who drank voluntarily, with the incidence of emesis escalated in both groups when the target volume of $240 \mathrm{ml}$ was reached. Further study has also reported that early oral fluid administration in adult patients undergoing non-gastrointestinal surgery was safe with patients experiencing lower scales in thirst and oropharyngeal discomfort [5], and early postoperative oral hydration in small quantity in children was feasible without increasing the incidence of nausea, vomiting, choking, and aspiration [22]. Our study has further emphasized that early administration of oral fluid is feasible, safe, and associated with relived thirst and reduced incidence of postoperative nausea and vomiting in children who has the desire to drink. Such feasibility and safety observed were most likely attributable to our stringent criteria in patient assessment before allowing oral fluid in addition to close supervision and observation of fluid intake in the early phase.

There were some limitations to this study. We did not explore the optimal amount of fluids allowed after tonsillectomy. Furthermore, there was no blinding in the assessment of nausea/vomiting. Moreover, the long-term efficacy of a small amount of oral fluid for children undergoing tonsillectomy has not been determined, which warrants further studies.

\section{Conclusions}

In conclusion, the early administration of a small amount of oral fluid in children undergoing tonsil surgery and recovering from general anesthesia is not only safe but also effective in reducing postoperative thirst. The recovery of cough and swallowing reflex and muscle strength must be determined to ensure the safety of such practice.

Table 4 Comparison of incidence of nausea and vomiting between two groups

\begin{tabular}{|c|c|c|c|}
\hline Items & Study group $(N=138)$ & Control group $(N=130)$ & $P$-value \\
\hline \multicolumn{4}{|l|}{ Incidence of nausea at PACU, $n(\%)$} \\
\hline Before drinking at the PACU & 0 & $2(1.5)$ & 0.234 \\
\hline 20 min after drinking at PACU & $2(1.4)$ & $3(2.3)$ & 0.676 \\
\hline \multicolumn{4}{|l|}{ Incidence of vomiting at PACU, $\mathrm{n}(\%)$} \\
\hline Before drinking at the PACU & 0 & 0 & \\
\hline 20 min after drinking at PACU & $1(0.7)$ & $1(0.8)$ & 1.000 \\
\hline Nausea and vomiting before returning to the ward for food, $n(\%)$ & 0 & $1(0.8)$ & 0.485 \\
\hline Nausea after eating in the ward, $\mathrm{n}(\%)$ & 0 & $4(3.1)$ & 0.054 \\
\hline Vomiting after eating in the ward, $n(\%)$ & 0 & $3(2.3)$ & 0.113 \\
\hline Nausea and vomiting occurred $24 \mathrm{~h}$ after surgery & $3(2.2)$ & $2(1.5)$ & 1.000 \\
\hline
\end{tabular}




\section{Abbreviations}

ASA: American Society of Anesthesiologists; PACU: Post-Anesthesia Care Unit

\section{Acknowledgements}

The authors appreciate the 300 research subjects for their devotion and cooperation.

\section{Authors' contributions}

MH W and CQ L were involved in the design of this study, data collection, analysis and interpretation of data, drafting and revising the manuscript. XQ $Z$ and $A N J$ assisted in data collection, analysis, and interpretation. XR Y made substantive intellectual contributions to the interpretation of data and draft of the manuscript. The authors had read and approved the final manuscript.

\section{Funding}

Not

\section{Availability of data and materials}

The data that supports the findings of this study are available on request from the corresponding author. The data are not publicly available due to privacy or ethical restrictions.

\section{Ethics approval and consent to participate}

Ethical approval for the study was obtained from the Biomedical Ethics Committee of West China Hospital of Sichuan University (2017 Review No. 231), and written informed consent was obtained from the guardian of the sick children, with the trial registration number ChiCTR1800020058 (registered on the 12th December 2018). The findings of the study were reported according to the CONSORT guidelines.

\section{Consent for publication}

Not Applicable.

\section{Competing interests}

The authors declare no conflict of interest.

\section{Author details}

${ }^{1}$ Department of Liver Surgery, West China Hospital / West China School of Nursing, Sichuan University, No. 37, Guoxue Alley, Wuhou District, Chengdu, Sichuan 610041, China. ${ }^{2}$ West China School of Nursing / Operating Room of Anesthesia Surgery Center, West China Hospital, Sichuan University, No. 37, Guoxue Alley, Wuhou District, Chengdu, Sichuan 610041, China. ${ }^{3}$ Department of Anesthesiology, Anesthesia Surgery Center of West China Hospital / West China School of Nursing, Sichuan University, No. 37, Guoxue Alley, Wuhou District, Chengdu, Sichuan 610041, China.

Received: 27 September 2020 Accepted: 29 December 2020 Published online: 11 January 2021

\section{References}

1. Apfelbaum $J$, Silverstein JH, Chung FF, Connis RT, Fillmore RB, Hunt SE, American Society of Anesthesiologists Task Force on Postanesthetic Care, et al. Practice guidelines for postanesthetic care: an updated report by the American Society of Anesthesiologists Task Force on Postanesthetic Care. Anesthesiology. 2013;118(2):291-307. https://doi.org/10.1097/ALN Ob013e31827773e9.

2. Mauermann E, Clamer D, Ruppen W, Bandschapp O. Association between intra-operative fentanyl dosing and postoperativenausea/vomiting and pain: a prospective cohort study. Eur J Anaesthesiol. 2019;36(11):871-80. https://doi.org/10.1097/EJA.0000000000001081

3. Sato C, Toraiwa S, Kobayashi T, Onodera N, Nakamura S. Influence of intraoperative fentanyl and remifentanil infusion on early postoperative oral intake after general anesthesia. Masui. 2012;61(9):1018-22.

4. Mercan A, El-Kerdawy E, Bhavsaar B, Bakhamees HS. The effect of timing and temperature of oral fluids ingested after minor surgery in preschoo children on vomiting: a prospective, randomized, clinical study. Paediatr Anaesth. 2011;21(10):1066-70. https://doi.org/10.1111/j.1460-9592.2011. 03626.x
5. Yin XR, Ye L, Zhao L, Li LS, Song JP. Early versus delayed postoperative oral hydration after general anesthesia: a prospective randomized trial. Int J Clin Exp Med. 2014;7(10):3491-6.

6. Yin X, Zeng X, Wang T, Dong B, Wu M, Jia A, et al. Early versus delayed postoperative oral hydration in children following general anesthesia: a prospective randomized trial. BMC Anesthesiol. 2020;20(1):174. https://doi. org/10.1186/s12871-020-01086-8.

7. Wu MH, Yang L, Zeng XQ, Wang T, Jia AN, Zuo YX, et al. Safety and feasibility of early oral hydration in the postanesthesia care unit after laparoscopic cholecystectomy: a prospective, randomized, and controlled study. J Perianesth Nurs. 2019;34(2):425-30. https://doi.org/10.1016/j.jopan. 2018.06.093

8. Sentürk M, Orhan Sungur M, Sungur Z. Fluid management in thoracic anesthesia. Minerva Anestesiol. 2017;83(6):652-9. https://doi.org/10.23736/ S0375-9393.17.11760-8.

9. Sahin E, Terzioglu F. The effect of gum chewing, early oral hydration, and early mobilization on intestinal motility after cesarean birth. Worldviews Evid Based Nurs. 2015;12(6):380-8. https://doi.org/10.1111/wvn.12125.

10. Cai YG, Wen TP. Treatment of children snore by tonsillectomy combined with nasal endoscopic-assisted adenoidectomy. J Clin Exp Med. 2011;10(11): $842-3$.

11. Stuck BA, Götte $K$, Windfuhr JP, Genzwürker $H$, Schroten $H$, Tenenbaum T. Tonsillectomy in children. Dtsch Arztebl Int. 2008;105(49):852-61. https://doi. org/10.3238/arztebl.2008.0852.

12. Liu HJ, Weng $H$, Wang JG. Effects of dexmedetomidine on emergence agitation after tonsillectomy. J Clin Anesthesiol. 2012;28(8):772-4.

13. Bao Y, Shi DP, Feng WZ. Research progress of restlessness in children with general anesthesia in the wake period. J Clin Anesthesiol. 2010;26(2):183-4.

14. Yang WY, Wang CQ, Heng XH. Advances in the study of drug use before anesthesia in children. J Clin Anesthesiol. 2011;27(9):931-3.

15. Fan $\mathrm{H}$, Tao $\mathrm{F}$, Wan HF, Luo H. A prospective cohort study of the risk factors of emergence agitation in pediatric after general anesthesia. Natl Med $J$ China. 2012;92(17):1194-7.

16. Yang FM. Dietary nursing experience after tonsillectomy in children. J Psychol. 2012;214:240.

17. Liu ZH, Liu XM, Li YZ. Nursing care after tonsillectomy. Chin Foreign Health Abstr. 2012:9(9):361-2

18. Bennett AM, Emery PJ. A significant reduction in paediatric posttonsillectomy vomiting through audit. Ann R Coll Surg Engl. 2008;90(3):22630. https://doi.org/10.1308/003588408X261591.

19. Chen XP. Surgery. Beijing: People's Medical Publisher; 2006. p. 57.

20. Jin F, Norris A, Chung F, Ganeshram T. Should adult patients drink fluids before discharge from ambulatory surgery? Anesth Analg. 1998;87(2):30611. https://doi.org/10.1097/00000539-199808000-00013.

21. Tabaee A, Lin JW, Dupiton V, Jones JE. The role of oral fluid intake following adeno-tonsillectomy. Int J Pediatr Otorhinolaryngol. 2006;70(7):1159-64. https://doi.org/10.1016/j.jporl.2005.11.015

22. Yin $X R$, Tan L, Liao $Y$, Liu Y, Yin Y, Guo $\perp$. Feasibility of a small amount of water intake at early stage after general anesthesia in children. Chin J Anesthesiol. 2012:32(3):282-3.

\section{Publisher's Note}

Springer Nature remains neutral with regard to jurisdictional claims in published maps and institutional affiliations.

Ready to submit your research? Choose BMC and benefit from:

- fast, convenient online submission

- thorough peer review by experienced researchers in your field

- rapid publication on acceptance

- support for research data, including large and complex data types

- gold Open Access which fosters wider collaboration and increased citations

- maximum visibility for your research: over $100 \mathrm{M}$ website views per year

At BMC, research is always in progress.

Learn more biomedcentral.com/submissions 